\title{
Conflicts between International Accreditation Standards and Local Institutions: The Case about a Japanese Business School
}

\author{
Shinji Ishikawa and Yokoyama Kenji
}

Department of Business and Management, Ritsumeikan Asia Pacific University, Ōita, Japan

Corresponding author: Prof. Yokoyama Kenji, Ph.D., Vice-President and Executive Dean, Department of Business and Management, Ritsumeikan Asia Pacific University, Ōita, Japan, Tel: +81 977-78-1000; Fax: +81-977-78-1001; E-mail: yokoyama@apu.ac.jp

Received date: February 07, 2017; Accepted date: February 16, 2017; Published date: February 20, 2017

Copyright: (c) 2017 Ishikawa S, et al. This is an open-access article distributed under the terms of the Creative Commons Attribution License, which permits unrestricted use, distribution, and reproduction in any medium, provided the original author and source are credited.

Citation: Ishikawa S, Yokoyama K. Conflicts between International Accreditation Standards and Local Institutions: The Case about a Japanese Business School. Br J Res 2017, 4:3.

\section{Abstract}

This paper utilizes a Japanese business school as an example to clarify the issues faced in applying American accreditation standards to the Japanese education system all while aiming to shed light on the root causes of these issues.

According to the Association to Advance Collegiate Schools of Business (AACSB International; hereinafter "AACSB") standards, procedures for accreditation must be completed on the basis of mission. On the other hand, the concept of mission did not exist in Japan's university management until recently. Mission-based organizations and activities are not an easy matter for business schools in countries where the concept of mission is not common.

When a Japanese university attempts to obtain accreditation from a non-Japanese entity such as AACSB, difficulties and challenges mainly result from the differences between the institutions and systems forged from marketoriented situations and those created without a consciousness of the market.

Historically, not many institutions of higher education in Japan issued doctoral degrees. More academically prone students tended to go straight into the business world with only a bachelor degree. Some of these students became university professors, but to this day, they do not hold doctoral degrees. Likewise, in the realm of business education, it remains difficult to secure qualified faculty in Japan who comply with the AACSB standards.

When a Japanese university attempts to obtain accreditation from a non-Japanese entity such as AACSB, difficulties and challenges mainly result from the differences between the institutions and systems forged from marketoriented situations and those created without a consciousness of the market. Now that some business schools in Japan find themselves compelled to compete in the global market, they are trying to take full advantage of international accreditation and the influence it holds. As we show in this paper, international accreditation is already starting to play an integral role in the transformation of business education in Japan, and going forward, it could be a driving force for reform in Japanese higher education as a whole.

Keywords: AACSB standards; Ritsumeikan Asia Pacific University (APU); International business accreditation; Mission; Faculty qualifications; Assurance of learning

\section{Introduction}

\section{International accreditation}

Japanese universities have focused on third-party accreditation for higher education as one of the issues pertaining to the assurance of learning in Japan's higher education institutions. In the United States, this kind of accreditation constitutes the only institutional grounds for justifying the research and educational activities of universities and colleges.

On the contrary, Japan did not adopt this kind of accreditation system until recently. The Government of Japan used to provide a new university or college with a permit for establishment only when the university satisfied the Standards for Establishment. Universities are expected to set their own enrollment capacities, and they are not allowed to accept more students than said capacity. According to the number of enrollees, universities must prepare a certain number of qualified faculty, classrooms, and other necessary equipment and facilities.

Meanwhile, Japan's birthrates have been declining since the turn of the century. This phenomenon could lead excess competition and a subsequent deterioration of quality of in higher education. The drastic change of demography will cause the polarization between the selected universities and the nonselected. Mr. Shimomura, a former minister of education, said in a TV interview that the universities who would not endeavor to improve their education could not survive in the coming harsh competition. "One tactic for survival is regarded as getting a highly appreciated accreditation", he added. 
In 2004, the Accreditation Evaluation Act was enacted, making it obligatory for higher education institutions to undergo regular accreditation assessments [1].

There are two types of accreditation in Japan: institutional accreditation and specialized accreditation. The former is for a university or a college, while the latter is for a school, a program or a department. Institutional accreditation is provided by accreditation organizations which only operate domestically. On the other hand, some of the specialized accreditation organizations also operate internationally. This is especially true for business and management education.

In these situations, what draws attention is the global development and activities of accreditation agencies for business and management education. Among them are the Association to Advance Collegiate Schools of Business (AACSB), in Tampa, Florida in the United States, the Association of MBAs (AMBA) in London, England, and the European Foundation for Management Education (EFMD) in Brussels, Belgium. These organizations are competing intensely with one another to become the premier agency offering the de facto standard for business education.

To date, AACSB accredited many institutions. Although its accreditation activities used to be confined to the United States, it has since expanded its scope to encompass to Australia, New Zealand, Southeast Asia, and Far East Asia. Japan, which was long the only country in Asia that seemed uninterested in international accreditation, has belatedly embraced the idea of obtaining accreditation from international accreditation agencies such as those mentioned above.

\section{Differences in accreditation between Japan and the United States}

In the United States, groups of universities and colleges voluntarily form accreditation organizations which establish sets of rules and regulations. The member universities of each organization must undergo accreditation within a certain period. The federal government only provides scholarships and research subsidies to students and faculty of accredited universities.

The American accreditation system is similar to the Japanese one formally; however, some claim that the government has merely taken advantage of a system that the accreditation organizations have spent the past century establishing. Accredited universities do not receive any institutional support; support is only provided for students and faculty.

This university accreditation system is an evaluation system that is indigenous to the United States. Although state governments are involved in the establishment of universities, the official requirements for university establishment are more or less general in comparison to those of Japan. In some states, the system employed is essentially a process of notification. The state governments simply require new universities to be nonprofit entities. These establishment procedures only constituted the conferral of a provisional license. The state governments provide approval but do not guarantee that a university is suitable for granting degrees or providing an adequate level of higher education.

In this respect, the American system is largely different from the Japanese system in which the national government is expected to be held accountable for the maturity of a university by applying strict establishment standards. It is a matter of course to be strict about the foundation of a university if the government is to be held responsible for the future success and assurance of learning of said institution. However, the revised School Education Act of 2002 insinuates that Japan has changed its direction from "pre-inspection" to "post-inspection" like the United States. This is why accreditation has drawn attention as a means of post-inspection in Japan.

In the United States, once establishment is approved, everything about university management is entrusted to the university itself no matter what kind of entity it is. This means that the state government is not committed to assuring of learning of any given university: this task is entrusted to the university and its accreditation organization.

If a university that applies for its establishment has been accredited, then the establishment of said university will be approved with no conditions. In other words, what decides the existence of a university is the "market" in the broadest sense. In such a case, what matters most for universities to assure and improve the quality of education is that the accreditation organization is a voluntary entity. Japanese universities and colleges always pay heed to the statements of the Ministry of Education, Culture, Sports, Science and Technology (MEXT), while American ones direct their attention to the policies of accreditation organizations rather than state and/or federal governments [2].

The American system brings with it several risks. One of them is that inappropriate universities, or degree mills, can emerge. This is not only a domestic issue but also an international one, and it has the potential to hurt the credibility of American higher education.

The American does not depend on the government to solve this problem, nor would they want the government to be involved in it. University officials are, in principle, cautious about government intervention in higher education.

\section{Purposes of the paper}

The structures and systems of higher education are decided by government regulations and ordinances in Japan, while those in the United States are formed through accreditation, or in other words, through the "market".

On the other hand, in some fields of higher education such as business and management, international competition for recruiting is intensifying. Some business schools have been trying to obtain accreditation from AACSB, which was initially developed as an American accreditation organization. In this scenario, certain kinds of problems and conflicts can be observed when a university or college is forced to adapt to standards based upon the American context to the domestic (i.e., Japanese) education system. 
In this paper, I utilize a Japanese business school as an example to clarify the issues faced in applying American accreditation standards to the Japanese education system all while aiming to shed light on the root causes of these issues.

\section{Materials, methods and theories}

The theories on which this article depends are the theories of path dependency, strategic complimentarity and institutional complimentarity in the field of comparative institutional analysis. The path dependency says that the path of change depends on the default or the initial value. The theory of strategic complimentarity can be explained like people strategically opt for what other people or organizations have adopted. The theory of institutional complimentarity says that things would not change easily once they have been formed as a system, since a system is closely related with other systems and the system cannot be changed without influencing on the others.

The methodology that this article has adopted is a case study. The institution that the case handles is a Japanese business school that was established within the Japanese regulations and institutions. This business school tried to obtain an international accreditation, whose standards were based upon the American institutions and regulations, since it is in need of making itself competitive by obtaining an international accreditation. This case describes how the Japanese business school had to accept new systems and institutions based upon the American institutions.

All the materials used in this article are what the business school dealt with actually. This article used them as the primary data and information. It should be noted that detailed comments and advice that the peer review team and the Initial Accreditation Committee of AACSB provided us with should be strictly confidential and were not used for the contractual reason.

\section{APU Business Unit Challenge}

\section{Introduction}

Ritsumeikan Asia Pacific University (APU) was founded in April 2000 in Beppu City, Oita Prefecture as Japan's first truly international university. As of 2017, it comprises two undergraduate colleges, the College of International Management and the College of Asia Pacific Studies, and two graduate schools, the Graduate School of Management and the Graduate School of Asia Pacific Studies [3].

To realize a multicultural campus environment, APU defined the concept of the "Three 50s" (i.e., 50\% international student ratio, $50 \%$ non-Japanese faculty ratio, and at least 50 countries and regions represented by the student body) as it prepared to open its doors, and all three of these were nearly achieved in the university's first year of operation. Another unique feature of APU is dual language education. This is a system by which $80 \%$ of undergraduate classes are held in both Japanese and
English. Meanwhile, the programs in the graduate schools are offered in English only.

APU is the leading international university among Japan's around 800 universities, and many universities in Japan view APU as the role model for internationalization.

APU's College of International Management and Graduate School of Management (collectively referred to as "APU Business Unit") undertook to obtain business accreditation from the Association to Advance Collegiate Schools of Business (AACSB) for the sake of international quality assurance. Although APU and the APU Business Unit were ahead of the curve in terms of internationalization.

The Unit commenced the accreditation process in 2008 in accordance with the 2003 Business Standards. In 2013, AACSB introduced the new 2013 Business Standards, which include the three new conceptual pillars of Engagement, Innovation, and Impact. Several standards were reorganized and combined, and many of the terms relating to the accreditation process also changed.

This paper outlines the older process that the APU Business Unit went through, so the terminology from the previous standards was used. What's more, the 2003 Business Standards were revised almost annually, so unless otherwise noted, the standards referred to in this paper are the 2013 revised standards.

The AACSB 2003 Business Standards are composed of the following 21 standards. This paper focuses primarily on Standards 1, 2, 10, 15-18, and 20-the standards on which the APU Business Unit dedicated particular energy.

\section{Critical standards}

First, Standard 1, which pertains to the Mission Statement, is the most important of the AACSB standards. AACSB accreditation is referred to as a mission-driven or missionoriented process, so the Mission Statement serves as the backbone of the process.

AACSB recommends every business school to define its own Mission Statement and undertake all of its activities in accordance with said Mission Statement. In Japan and around the world, the term "business school" usually means the body offering an MBA Program, but for the purposes of AACSB, it refers to the Business Unit (sometimes called the Business Accreditation Unit). The Business Unit refers to the organization in charge of providing business and management education programs.

Standard 2 pertains to the research achievements of the business school, which AACSB refers to as Intellectual Contributions (ICS). As the standard notes, AACSB requires ICs to be "consistent with the mission." Standard 2 is closely tied to Standard 10, which is discussed later.

Standard 10 pertains to Faculty Qualifications. AACSB requires business schools to classify its faculty members including parttime faculty members into one of three categoriesAcademically Qualified (“AQ"), Professionally Qualified (“PQ"), 
and Other-according a combination of the degrees they hold, their management experience in the business world, their ICs or Professional Contributions (PCs) over the past five years, and/or the maintenance of their professional status. PCs are such as consulting services for companies relating to their professional status.

AACSB presents the following basic approach to $A Q$ and $P Q$, and each business school must define these terms in accordance with their respective missions. Faculty members who do not fall under either $\mathrm{AQ}$ or $\mathrm{PQ}$ are classified as other. For the entire business school and each program, at least $50 \%$ of faculty must be $A Q$, while the total percentage of $A Q$ and $P Q$ faculty combined must be at least $90 \%$.

The APU Business Unit has defined $A Q$ and $P Q$ as follows:

- AQ: Holds a PhD and has published two articles in peerreviewed journals, and has one IC or one PC in the past five years.

- PQ: Holds a master's degree or professional certification (e.g., CPA), has management experience in a company, and has two of totaling IC(s) or/and $P C(s)$ in the past five years.

That being said, between the Eligibility Application and the Peer Review Visit (mentioned later), some exceptions were made to this rule, and measures were in place to lighten the requirements for faculty holding executive positions. These measures were completely eliminated after the commencement of the one-year deferral process, as is discussed later.

Standards 15 through Standard 18 and Standard 20 all pertain to Assurance of Learning (AOL), or in other words, the assessment of learning outcomes. Standard 15 is concerned with the curriculum management process. Business schools are required to list the learning experiences for specific knowledge and skill areas. This process is expected to generate and provide assurance for said learning experiences [4].

Standard 16 pertains to undergraduate learning goals, which are to be aligned to the business school's mission. Standard 17, which is related to Standards 15 and 16, is concerned with the actions taken to realize the learning goals.

Standard 18 is concerned with the actions taken to realize the learning goals of the master's level degree in general management (e.g., MBA), while Standard 20 deals with master's level learning goals

In Standards 16 and 18, AACSB requires business schools to define both learning goals and learning objectives. While learning goals are more abstract and difficult to measure, learning objectives are meant to be measurable.

Furthermore, an AACSB white paper entitled AACSB Assurance of Learning Standards: An Interpretation explains that with regard to the AOL process, "the focus is the program," not the individual courses, students, or faculty members. It also presents the following approach to programs.

AACSB requires business schools to carry out the actions listed in all five of these steps, and the completion of this process is called "closing the loop."
The Assessment Process is explained as follows;

Step 1: Establish learning goals and objectives;

Step 2: Alignment of curricula with adopted goals;

Step 3: Identification of assessment instruments and measures;

Step 4: Collection, analyzing, and dissemination of assessment information;

Step 5: Using assessment information for continuous improvement including documentation that the process is being carried out on an ongoing, systematic basis.

As indicated in Step 5, loop means that business schools engage in the continuous improvement of its curriculum by carrying out the actions in the first four steps. After issues have been identified in Steps 2 through 4 of the AOL process, a detailed action plan must be formulated in Step 5 . Only once this has been implemented can the loop be considered closed.

\section{Details of accreditation process in the APU Business Unit}

Eligibility application: In the Eligibility Application, we defined the APU Business Unit to consist of APM and GSM, and we submitted this application to AACSB in August 2008.

In October 2008, the AACSB Pre-Accreditation Committee (PAC) approved the APU Business Unit's Eligibility Application. Upon the approval of our Eligibility Application, AACSB proposed that a person from a school in thels serve as our Mentor. It also expressed concern over a lack of information pertaining to Standards 1, 10, 16, 18, and 19.

With regard to Standard 1, it is not always common practice in Japan for universities, colleges, and graduate schools to have mission statements as they are naturally expected to comply with MEXT ordinances and the university accreditation process (which is discussed later in this document). For this reason, we did not have a clear mission statement in place at the time of the Eligibility Application [5-8].

In the AACSB accreditation process, it is often said that business schools with undergraduate programs tend to struggle with Standard 10 (Faculty Qualifications) and the AOL standards, and the APU Business Unit was no different.

When we submitted our Eligibility Application, we addressed Standard 10 in light of the other AACSB Business Accreditation Standards, but we had yet to define our own standards for $A Q$ and $P Q$. For example, we had classified several faculty members with master's degrees as $A Q$, but the AACSB Business Accreditation Standards indicated the following rules for faculty to be classified as AQ. This led the APU Business Unit to define the possession of a doctoral degree as a requirement for $A Q$ status:

- A doctoral degree in the area in which the individual teaches.

- A doctoral degree in a business field, but primary teaching responsibility in a business field that is not the area of academic preparation. 
- A doctoral degree outside of business, but primary teaching responsibilities that incorporate the area of academic preparation.

- A doctoral degree outside of business and primary teaching responsibilities that do not incorporate the area of academic preparation.

- A specialized graduate degree in taxation.

- Substantial specialized coursework and/or demonstrated research competence in the primary field of teaching responsibilities, but no research doctoral degree.

With respect to AOL, the APU Business Unit at that time was not conducting a form of learning outcomes assessment, as was pointed out by the PAC. AACSB's AOL white paper explains the context in which AOL was adopted as follows: "In 2003, AACSB standards were changed to reflect the maturity of the "outcomes assessment" movement and need for improved accountability measures."

Meanwhile, in 2008, the year in which the APU Business Unit submitted its Eligibility Application, APU as a university (in other words, an institution) received a Peer Review Team visit from the Japan University Accreditation Association ("JUAA") for institutional accreditation and was subsequently accredited by JUAA in 2009.

In 2002, MEXT revised the School Education Act to create a system whereby all of Japan's national, public, and private universities would have to undergo accreditation at routine intervals by a Minister of MEXT-designated accreditation agency. Thus, accreditation became mandatory for all universities once this law was enacted in 2004. This accreditation, which comprehensively assesses whether a university conducts education, research, administration, and facilities management in accordance with its mission, is performed at least once every seven years [9].

APU opened in 2000 and underwent its first mandatory accreditation evaluation in 2008; however, at that time, JUAA did not require universities to conduct learning outcomes assessment processes for the first phase of mandatory accreditation (AY2004-AY2010). Therefore, when we take into consideration the situation surrounding Japan's universities and business schools, nothing could be done about the fact that the APU Business Unit was not assessing learning outcomes at the time it submitted its Eligibility Application.

\section{Pre-accreditation process}

In this section, we discuss the submission of our Accreditation Plan based on the AACSB Business Accreditation Standards, the letter from the PAC, the letter from the Initial Accreditation Committee, the submission of our Progress Report, and the agreement of the IAC, Mentor and the APU Business Unit on the transition to the Initial Accreditation Process.

After the Mentor visit in February 2009, the APU Business Unit worked to make improvements with particular focus on Standards 1 and 10 and the AOL Standards.

More specifically, we revised the mission statement and invited a lecturer from the United States to help deepen our understanding of AOL. We invited our mentor to visit again in December 2009 and asked him for his advice.

After undertaking these improvements, the APU Business Unit submitted its Accreditation Plan to AACSB in April 2010. In the Accreditation Plan, the APU Business Unit had to clearly indicate whether or not it had achieved each standard and describe who or what organization was responsible for achieving those standards which had not been satisfied yet as well as how it planned to go about that process.

The Accreditation Plan must be approved by PAC and IAC, the committee in charge of screening business schools attempting AACSB accreditation for the first time. Only then can a business school transition to the Pre-accreditation Process.

In some cases, if there are issues with the Accreditation Plan, it must be revised and resubmitted [10].

The Accreditation Plan that the APU Business Unit submitted was accepted by the PAC and the IAC, after which time the PAC and IAC sent letters to the APU Business Unit in July and August 2010, respectively.

The PAC refers to the five-step $A O L$ process outlined in the AOL white paper. By the time the APU Business Unit submitted its Accreditation Plan, it had only completed Step 1 (Establish learning goals and objectives).

\section{APM learning goals}

- APM graduates will understand Business Ethics theory.

- APM graduates will obtain the Fundamental Knowledge of Discipline.

- APM graduates will learn Intercultural Communication Skills.

- APM graduates will acquire Global Perspectives in business management.

\section{GSM learning goals}

- GSM graduates will understand Business Ethics theory.

- GSM graduates will obtain the Advanced Knowledge of Discipline.

- GSM graduates will have a Sense of Innovation.

- GSM graduates will acquire Global Perspectives in business management.

The visit to take place in December of 2013 refers to the Peer Review Team Visit. The actual Peer Review Visit occurred in January 2015 and March 2016. The first one was scheduled for October 2014 but postponed due to a typhoon.

The PAC refers to the fact that only $41.82 \%$ of faculty members were $A Q$ and $62.63 \%$ were either $A Q$ or $P Q$ at the point when the APU Business Unit submitted its Accreditation Plan.

In the Accreditation Plan, we listed the respective $A Q$ and $P Q$ figures for the entire Business Unit, the undergraduate program in APM, and the master's program in GSM in accordance with Standard 10.

The letter mentioned the low $A Q$ and PQ numbers for APM as a whole and indirectly indicated that figures were also low for the Marketing field. 
Meanwhile, we created the following APM and GSM mission statements based on the feedback from the IAC.

The Business Unit has mission statements that are appropriate for the undergraduate and the graduate levels respectively. The statements are clearly founded on and consonant with the "Declaration on the Occasion of the Opening of APU".

Based on the vision of freedom, peace and humanity, international mutual understanding, and the future shape of the Asia Pacific region:

- The mission of the College of International Management (APM) is to cultivate human resources with strong business ethics that will play an active role in resolving management issues at globalizing enterprises and other organizations by imparting fundamental knowledge in management, enhancing intercultural communication skills and upholding cultural diversities.

- The mission of the Graduate School of Management (GSM) is to cultivate creative well-rounded professionals and leaders who will play a central role in resolving management issues at globalizing enterprises and other organizations by imparting advanced management skills, a good understanding of business ethics and a deep insight into globalization.

These statements remain as is at the time of writing. When we were at the process of drafting the Accreditation Plan, we were discussing the mission statements and the learning goals at the same time, so one can see that we did not fully understand the need for consistency between the mission and the ICs at that time. We finally grasped exactly what it meant to ensure that our ICs were in alignment with the mission by the time of the Peer Review Team visit in 2015.

\section{Submission of progress reports (June 2011-May 2013)}

After receiving the aforementioned letters from the PAC and IAC, the APU Business Unit began taking action to meet those standards we had yet to satisfy.

The APU Business Unit took the following actions with regard to Standard 10 (Faculty Qualifications):

- The Dean of the Business Unit held interviews with faculty members classified as Other and those at risk of becoming classified as Other to encourage them to create Intellectual Contributions (namely, publish papers in peer-reviewed journals).

- We informed tenure track faculty that they cannot obtain tenure if they do not fulfill the $A Q$ standards. (Note: the tenure track system affords faculty hired on five-year fixed term contracts the chance to earn tenure provided they meet the requirements for research achievements.) Strict enforcement of this rule actually led to a few cases where fixed-term faculty was unable to gain tenure.

- We decided not to hire Supporting Faculty with neither AQ nor PQ status as part-time faculty.
The APU Business Unit took the following actions with regard to the AOL Standards:

- Summarized actions taken for Steps 2 through 5 in the AOL white paper.

- Established the AOL Development Team in the Business Unit and convened meetings on AOL almost weekly.

- Invited assessment experts from the United States to deepen our understanding of $\mathrm{AOL}$ and held a session in which an AACSB-accredited business school from South Korea shared its experience with us.

- Send faculty to participate in AACSB-sponsored AOL seminars and conferences.

The APU Business Unit summarized these actions in a Progress Report that it submitted to AACSB.

After this series of communications up through May 2013, the IAC sent a letter to the APU Business Unit in August 2013 stating its intention to move the school to the Initial Accreditation Process.

\section{Initial accreditation process}

In this section we will discuss the following: submission of the Initial Accreditation Application, decision of the Peer Review Team Chair and members, the Peer Review Team Chair's previsit, submission of the Self Evaluation Report, changes to the Peer Review Team members, receipt of a pre-visit letter from the Peer Review Team, the Peer Review Team visit, the receipt of the Peer Review Team report, and the receipt of a letter from the Initial Accreditation Committee.

To move to the Initial Accreditation Process, the APU Business Unit had to submit an Initial Accreditation Application in the format designated by AACSB.

The biggest difference between AACSB accreditation and Japanese accreditation (which is also called institutional certified evaluation) is the fact that the following matters need to be communicated to AACSB before the Peer Review Visit:

Using AACSB Data Direct, an online service that provides the basic information for all AACSB accredited business schools, the APU Business Unit selected 12 schools as Comparable Peers, six schools for its Competitive Group, and eight schools for its Aspirant Group and reported these to AACSB.

The APU Business Unit also notified AACSB of its nominations for Business Team members, which were made by tapping into the personal networks of the APU Business Unit management team, and we asked AACSB to refrain from selecting members from business schools in countries with which Japan has diplomatic conflicts.

As the request to nominate schools as Comparable Peers, Competitive Group, and Aspirant Group shows, the APU Business Unit learned from the Initial Accreditation process the need to approach business school administration in a businesslike manner. This nomination process also reveals the relative importance that AACSB places on peer reviewing in the accreditation process. 
In the Pre-accreditation Process, Mentors support the business schools, but once the schools submit their Initial Accreditation Applications, they must write their Self Evaluation Reports (to be discussed later) and prepare for Peer Review Team visits while receiving support from their respective Peer Review Team Chairs.

AACSB appointed three faculty members as the Peer Review Team for the APU Business Unit.

AACSB urges business schools to invite their Peer Review Team Chairs for a pre-visit before the full Peer Review Team visit. For this reason, the APU Business Unit invited its Peer Review Team Chair, for a pre-visit. During the half-day pre-visit, we gave an overview of the APU Business Unit to the Chair and explained how we were working to address some of the more important AACSB Business Standards. We also gave him a tour of the campus and arranged student interviews with him. This visit was a chance to help the Chair understand the APU Business Unit better; it bore no direct connection to the accreditation assessment.

The APU Business Unit wrote its Self-evaluation Report taking into account the feedback received during the pre-visit in February and submitted it to AACSB. Being able to receive feedback from the Peer Review Team Chair during the Self Evaluation Report drafting process is another point where AACSB accreditation differs from Japanese accreditation.

To ensure the Self Evaluation Report was as accurate as possible, the APU Business Unit management team visited the Peer Review Team Chair in May 2014 to receive his advice.

In the Self Evaluation Report, a business school must assess the activities it has undertaken to address each standard. For this report, the APU Business Unit was able to indicate that it satisfied all of the standards.

The Peer Review Team visit was originally scheduled for October 2014, but a large typhoon was forecast to approach the APU campus immediately before the visit. The APU Business Unit discussed the matter with the Peer Review Team Chair and AACSB head office, and an agreement was made to postpone the Peer Review Team visit to January 2015.

The January 2015 Peer Review Team visit took place from the 18th to the 21st. Regarding findings about Standard 10, although adjustments have been made by both mentors and the AACSB in the pre-accreditation process, we determined that the faculty qualifications assumed by the AACSB are extremely strict. We later exchanged opinions with relevant individuals from business schools in other countries, and received the comment that it is extremely rare for someone with only a bachelor's degree to be classified as $P Q$, as this only applies to someone like Jack Ma, the founder of alibaba.com, teaching classes [11].

As to questions about $\mathrm{AOL}$ standards, we received severe comments that were not directed toward the measurement of learning objectives or "closing the loop," but rather toward our approach to the curriculum as a whole.

\section{Process from 2015 to 2016}

This section outlines actions taken to address unachieved standards, the submission of the final report, the Peer Review Team visit, and the official decision on accreditation.

The APU Business Unit received particularly severe comments from the Peer Review Team and Initial Accreditation Committee concerning Standard 15 and Standard 17 in the AOL Standards. The following section discusses the AOL Standards.

There were too few required subjects in APM, resulting in a structure with too many elective subjects and the comment about Standard 15 by the Peer Review Team, and creating a condition that gives rise to gaps and overlaps in classes provided by the College.

In the process leading up to receiving the Peer Review Team visit, the APU Business Unit had noticed to some extent that there was a shortage of required subjects. However, the Unit did not realize that this could be a factor resulting in the decision for a one-year deferral.

Generally, there are not necessarily many required subjects at the undergraduate level in Japanese business schools. In not only business schools, but also other undergraduate programs, there is usually no capstone course but rather a seminar course (called "zemi" in Japanese) in the third year and fourth year which is the final year. The seminar course has a small class size and is intended to allow students to further their studies in the field of their interest. Some instructors have students write thesis papers.

As mentioned above, Japan also has its own accreditation system to evaluate each program in a university. According to MEXT laws and accreditation standards, universities must formulate (1) a diploma policy, (2) a curriculum policy, and (3) an admissions policy for each program, and the three policies must be consistent with one another. That being said, the accreditation of JUAA differs from that of the AACSB in that it does not currently include a designation of what subjects should be required for business education or an evaluation of whether required subjects or capstone courses are offered.

To realize APU's "vision of freedom, peace and humanity, international mutual understanding, and the future shape of the Asia Pacific region," emphasis has also been placed on language education. As international students wishing to enter a Japanese university must usually take a primarily written entrance examination in Japan, prospective enrollees usually study at a Japanese language school in Japan or their own country to acquire a certain level of Japanese language proficiency before they attempt to gain acceptance to a university in Japan. At APU, those without any Japanese language proficiency at all may take the entrance examination in English to enroll. In their first and second years, these international students take classes in intensive Japanese language education as required subjects in addition to subjects in their major to reach a level of language proficiency that enables them to take major subjects taught in either Japanese or English from their third year. Japanese students also take intensive English classes as required subjects in their first and second years to reach a level of language 
proficiency that enables them to take major subjects taught in either Japanese or English from their third year onward. This concept is also applied in APM.

As mentioned in the introduction as well, this is an extremely unique initiative among Japanese universities, and by graduations, students not only have a high language proficiency, they have acquired a global perspective and intercultural communication skills, which are two of APM's learning goals, thereby earning APU great praise from Japanese companies operating on a global scale [12].

The APU Business Unit has undertaken the following actions to address standards other than the AOL Standards.

Standard 2: ICS were re-categorized. AACSB request every business school to classify ICs into Learning and pedagogical research, Contributions to practice (often referred to as applied research) or Discipline-based scholarship (often referred to as basic research).

After the Peer Review Visit the largest number of ICs in the APU Business Unit is now Contributions to Practice. In the future, we plan to officially acknowledge that the APU Business Unit places the most emphasis on Contributions to Practice.

Standard 10: Concerning $\mathrm{AQ} / \mathrm{PQ}$ standards, two problems noted during the Peer Review Team visit were that faculty with only a bachelor's degree were classified as PQ and that a Grantin-Aid subsidy could be counted as one peer reviewed journal article.

The AQ/PQ Standards were revised as follows in June 2015 by the APU Business Unit. In the revised standards, we will remove the various types of exceptions and reduced teaching loads that were being given to faculty members with administrative duties.

After the Peer Review Team visit in January 2015, the APU Business Unit undertook the improvements mentioned above and submitted a Report in December.

The final visit was held in March 2016. The visit lasted almost a full day, and the results were conveyed to the APU Business Unit by the chair of the team on Tuesday. The recommendation of the Peer Review Team is that the degree of programs offered by APU be granted initial accreditation and this will be reviewed in the Continuous Improvement Review which will occur in five years' time in 2021.

\section{Conclusion}

\section{Mission-based organization and activities}

According to the AACSB standards, procedures for accreditation must be completed on the basis of mission. On the other hand, the concept of mission did not exist in Japan's university management until recently. Mission-based organizations and activities are not an easy matter for business schools in countries where the concept of mission is not common.

The significance of mission can be explained from two different perspectives in the United States. One is religious.
Every individual has its own mission in life, and every kind of organization is expected to contribute to the development of the society in which it exists. This kind of mission is considered to be given by God. The other kind of mission is the mission of management. This originated with the religious concept of mission and was adapted to corporate management.

Both of these concepts of mission were new to Japanese universities except for those institutions founded by missionaries. What we had to do immediately after we decided to pursue accreditation was draft our mission statements. Because the APU Business Unit had no mission of its own, we initially quoted the Opening Declaration as our mission. Eventually, we drafted original mission statements for both the undergraduate program and the MBA program which contained a few excerpts from the Opening Declaration.

What turned out to be a more serious issue than the formulation of mission statements was the task of aligning the mission to other standards, such as the curriculum, research, and co-curricular activities? The influence of the mission is expected to extend even to budget allocations.

Unlike the procedures for university establishment in the United States, where the state government approves universities that have already been accepted by the market, the Japanese government approves university establishment premised on the notion that universities don't have to compete.

The reason why the importance of mission is emphasized in the United States is that it is the only medium or linkage between a university and the market. The process of AOL that stems from the mission is also a manner of competition in that it encourages the continuous improvement of education quality.

The above does not mean that Japan's universities have no mission or the significance of their existence. Almost all of them do possess education philosophy or mottoes, which include the character of mission. The same can be said in universities or business schools in other countries of Asia. It may not be a big challenge to extend them to goals and objectives. This is exactly what we did.

\section{Governance}

Governance refers to the way of controlling and overseeing the management of a business school. It works not only for monitoring if something immoral or illegal is occurring, but also for improving profitability. For the latter, a business school needs to have financial independence. Otherwise, it cannot take the necessary steps for executing strategies and tactics.

When it comes to governance, the situation in Japan looks obscure. A given college or institute does not function independently of the entire university, both financially and in terms of governance. Tuition and other income is directed to the accounting or financial section of the central entity. Because of these budget usage limitations, a business school cannot execute its own strategy and tactics independently from the university.

Japan's universities do have systems of governance, but they are designed to ensure democratic procedure; they do not 
necessarily work to improve productivity. Japanese universities focus on how to control management from the perspective of the faculty, while American university governance emphasizes controlling management from the standpoint of external stakeholders. Another big issue with Japan's business schools is that business schools are not independent from the whole entity of the university in terms of finance.

When a Japanese university attempts to obtain accreditation from a non-Japanese entity such as AACSB, difficulties and challenges mainly result from the differences between the institutions and systems forged from market-oriented situations and those created without a consciousness of the market.

Now that some business schools in Japan find themselves compelled to compete in the global market, they are trying to take full advantage of international accreditation and the influence it holds. As we show in this paper, international accreditation is already starting to play an integral role in the transformation of business education in Japan, and going forward, it could be a driving force for reform in Japanese higher education as a whole.

\section{Faculty sufficiency}

In the very least, a faculty member should possess an MBA or other relevant master's degree to be considered professionally qualified and a doctoral degree to be considered academically qualified.

Historically, not many institutions of higher education in Japan issued doctoral degrees. More academically prone students tended to go straight into the business world with only a bachelor degree. Some of these students became university professors, but to this day, they do not hold doctoral degrees. Likewise, in the realm of business education, it remains difficult to secure qualified faculty in Japan who comply with the AACSB standards.

This situation is worse in other Asian countries where there are not enough institutions of higher education to supply a sufficient number of doctoral program graduates. Actually, most of the accredited business schools in Asia employ faculty who obtained their doctoral degrees in other countries, such as the United States, Europe, or Australia. Hence, competition to acquire academically sufficient faculty in developing countries is intensifying.

\section{Assurance of learning}

Assurance of Learning ( $A O L)$ relates to the mission-based standards of AACSB. As mentioned earlier, every business school should have a mission, and these missions must be broken down into goals and objectives. Each course is expected to achieve one or a few of these objectives, and the level of achievement needs to be measured. The results of this process should be reflected in syllabus revisions and curriculum reforms.

One challenge about $A O L$ is that it is a new notion to almost all business schools and, as such, is not institutionalize; many business schools have to establish AOL measurement systems from the scratch. Another aspect of the difficulty of AOL is time. It usually takes a long time to complete the cycle because the results of the measurement must be reflected in the curriculum reforms at least twice. In Japan, school regulations must be revised every time the curriculum is modified, and new curricula are only applicable to new students. This means that multiple different curricula need to be maintained concurrently. Even if you obtain some results from the AOL process, it is not easy to change the curriculum accordingly.

\section{References}

1. AACSB International (2015) Business School Data Trends and 2015 List of Accredited Schools.

2. Masahiko A (2001) Towards a Comparative Institutional Analysis, MIT Press.

3. Becher T, Kogan M (1992) Process and Structure in Higher Education (2ndedn.). London, Routledge.

4. Bok D (2003) Universities in the marketplace: The commercialization of higher education. Princeton, NJ: Princeton University Press.

5. Chesbrough H (2003) Open Innovation: The new imperative for creating and profiting from technology. Cambridge, MA: Harvard Business School Press.

6. Fraguiero F, Thomas (2011) Strategic Leadership in the Business School: Keeping one step ahead. Cambridge: Cambridge University Press.

7. Thomas H, Michelle L, Thomas L, Alexander W (2016) Africa: The management Education Challenge, London: Emerald Books.

8. Khurana R (2007) From Higher Aims to Hired hands. Princeton, NJ: Princeton University Press.

9. Middlehurst R (2004) Changing Internal Governance, Higher Education Quarterly.

10. Masaaki M, Masahiro M, Horoto S (2013) Quality Assurance System in Globalization of Higher Education 27: 23-49.

11. Jun O (2014) International Comparison of University Governance. Reviews in Higher Education, Research Institute for Higher Education, Hiroshima University, Japan.

12. Carlile PR, Davidson SH, Freeman KW, Thomas H, Venkatraman N (2016) Reimaging Business Education: Insights and actions from the Business Education Jam, London: Emerald Books. 